\title{
Coupling a hydro-maritime model and remotely sensed techniques to assess the shoreline positioning uncertainty: the Marsala coast study case.
}

\author{
Giorgio Manno*, Carlo Lo Re, Giuseppe Ciraolo, Antonino Maltese \\ Department of Hydraulic Engineering and Environmental Applications (DIIAA), Università degli \\ Studi di Palermo, Viale delle Scienze Bldg. 8, Palermo, Italy
}

\begin{abstract}
The severe erosion phenomena affecting the Mediterranean coasts are strictly related to geophysical characteristics and socio-economic pressures. This suggests the need of monitoring and modelling the phenomenon in order to quantify its strength. In fact, the shoreline position, as well as its temporal evolution, provides important information for designing defence structures and for the development of a coastal management plan. The shoreline has a dynamic nature as it changes both in the short and long period. Those changes are caused by geo-morphological (e.g. bars and barrier island development etc.) and hydrodynamic (wave motion, tides and flows) processes, as well as by sudden and fast events such as sea storms, earthquakes and tsunamis ${ }^{[1]}$. The research examines the uncertainty in positioning the shoreline coupling remotely sensed images and a hydro-maritime model. Although the assessment accuracy strongly relies on data availability and consistency, the resulting assessment of the shoreline erosion and accretion is crucial for an overall understanding of the hydro-maritime geo-morphological interaction. The study case is the Marsala coastline (western coast of Sicily, Italy), named $12^{\text {th }}$ island physiographic unit. It is characterized by a low coast with sandy sediments from Holocene age. These sediments are in continuity of sedimentation on whitish debris composed by organogenic limestone from Pleistocene age. The diachronic analysis was carried out on both emerged and submerged parts of the beach and involves two distinct phases. In the first phase, geo-morphological in situ data have been compared with maps and georeferenced remote sensing images referred to the period 1994-2006. It allowed the identification of shoreline indicators ${ }^{[2]}$ such as the beach cross-section and the shoreline positioning including its spatial and temporal variations. It should be noted that the comparison between EO (Earth Observation) images and cartographic maps is subjected to several uncertainties, due to graphic error, geo-referencing accuracy and spatial resolution. Moreover tidal and climate waves data refer to an acquisition time different to that of the EO images. In the second phase, a maritime hydraulic modelling accounting for sea fluctuations has been performed. The run-up is related to wave's amplitude and phase, as well as to the composition and particle size of the beach sediments determining the beach slope ${ }^{[3]}$. Prior to run-up calculation, an investigation aiming to evaluate how the waves propagate from offshore to inshore (a third-generation spectral wave numerical model, SWAN - Simulating WAves Nearshore), has been carried out. Wave data have been acquired by a buoy belonging to the National Network Waves Data, located at the SW of the Mazara del Vallo harbour (Trapani), while tide data were recorded by the national marigraph of Porto Empedocle (Agrigento). The results allowed assessing the uncertainty and the consequent accuracy in the shoreline positioning for given slope, highlighting that it is not always possible to assess the shoreline rise and fall, for values lower than 10-15 m.
\end{abstract}

Keywords: coast, sandy beach, shoreline motion, waves run-up, tides.

\section{INTRODUCTION}

The shoreline erosion has direct consequences on geomorphological and ecological systems of the environment, since these are fragile systems, and extremely vulnerable to the antrophic impact. The shoreline is defined as the intersection between low sea tide and land surfaces, and spatially divides maritime and terrestrial water bodies ${ }^{[1]}$. A long time deficit of sediment income causes the regression of the shoreline, highlighting a local equilibrium rate of sediment and consequently the dynamical nature of the beach ${ }^{[4]}$. An accurate diachronic analysis requires the knowledge of the uncertainties in the shoreline positioning, which are both of hydraulic and remote sensing typologies. To detect the shoreline a variety of remote sensing operational methodologies can be used, working on images acquired in different parts of the electromagnetic spectrum. Remote sensing techniques include: aerial photography; shortwave or longwave

*manno@unipa.it; phone: +39 091 23896517; fax +390916657749

Remote Sensing for Agriculture, Ecosystems, and Hydrology XII, edited by Christopher M. U. Neale, Antonino Maltese, Proc. of SPIE Vol. 7824, 78241Z · C 2010 SPIE · CCC code: 0277-786X/10/\$18 - doi: 10.1117/12.865000 
airborne and space borne imaging; radar and LIDAR imaging. Furthermore, beach elevation within the intertidal zone is retrievable as well using ground survey, photogrammetry, SAR interferometry and laser ranging.

Traditionally, shoreline is three-dimensionally mapped by means of stereography on aerial photographs that, where available, are used to detect past shoreline position ${ }^{[2]}$. Near infrared and especially thermal infrared images can easily divide emerged and submerged domains, however their use is limited by a coarse spatial resolution. Optical images are characterized by higher spatial resolution, although needs to be pointed out that spectral the confusion due to turbidity, foam ${ }^{[1]}$ and beached submerged vegetation limits the accuracy of shoreline detection. SAR images can be acquired both all time and in all weather conditions, highlighting interesting potentialities, in spite of this signal echo from a sea surface depends heavily on the instantaneous sea state: waves may cause echo overwhelming the return from the emerged area ${ }^{[6]}$. According to Baghdadi et al. ${ }^{[7]}$, radar images yield a better definition of the shoreline with higher incidence angle, whereas Kim et al. ${ }^{[8]}$, report the higher accuracy in shoreline extraction the shorter the wavelength. LIDAR data intrinsically provide information about beach topography and near-shore bathymetry, shoreline can be extracted by intersecting LIDAR DEM and tidal datum surface ${ }^{[9]}$. The integration of complimentary information such as multispectral and geometric data ${ }^{[10]-[11]}$ through fusion techniques can overcome the shortcomings of individual methodologies.

However these studies allow retrieving only the instantaneous position of the shoreline that should also be considered from a temporal point of view. This research aims to take into account both wave and tide effects, acting during the image acquisition, on the user shoreline digitization. Each wave instantaneously determines the shoreline motion; the sea-wave of operational interest depends on the "ordinary sea-storm".

\section{METHODOLOGY}

Methodology includes several steps aiming to estimate the uncertainty in shoreline positioning by means of remote sensing data, namely: the geological and geomorphological characterization of the study area, in order to identify the sediment size and composition constituting the beach and determining its average slope; the diachronic analysis through orthophotos acquired for suitable period to identify erosion phenomena (10 years, from June 2006 to August 2005 in the present study); georeferencing, mosaicking of the images and digitization of the shoreline at a suitable scale; the characterization of the ordinary sea-storm for each wind direction and year; the wave motion propagation from offshore to nearshore; the estimation of the ordinary sea-storm maximum run-up; the displacement computation of the shoreline due to tide influence. Wave motion plays the most important role in characterize the instantaneous shoreline position ${ }^{[9]}$.

\subsection{Maritime hydraulic study}

In order to study the wave propagation from off to near shore the geographic aspect of the coast needs to be known. It allows calculating the wind sector in terms of angle amplitude, wind direction, blind sectors due to islands interferences. Once identified the wind sector, wave data recorded by the southern Mazara del Vallo buoy were acquired. The buoy is part of the National Wave-meter Network (Rete Ondametrica Nazionale) and is located ( $\left.37^{\circ} 31^{\prime} 00^{\prime \prime} \mathrm{N}, 12^{\circ} 32^{\prime} 00^{\prime \prime} \mathrm{E}\right)$ near the Mazara del Vallo harbor ${ }^{[12]}$.

\subsection{Statistical analysis of wave data}

In order to describe the methodology, the term "ordinary sea-storm" needs to be defined. A sea-storm is a succession of sea states during which the significant wave height, $H_{s}(t)$, is usually greater than a critical threshold, $h_{c r t}$, while it is lower than the threshold only for periods shorter than $\Delta t_{c r t}$. According to Boccotti ${ }^{[13]}$, the temporal, $\Delta t c r t$., and height, $h_{c r t}$, thresholds in Mediterranean Sea can be assumed equal to 12 hours and $1.5 \mathrm{~m}$ respectively. Within this work the prefix "ordinary" refers to a sea-storm that is reached at least once a year. To simply retrieve the ordinary value, records were filtered and sea storms were grouped, for each year, depending on $30^{\circ}$ sectors centred on 12 incoming directions ranging between $15^{\circ}$ and $345^{\circ} \mathrm{N}$. For each sea-storm height peak values were retrieved and the average time period was calculated.

\subsection{SWAN modelling}

SWAN is a third generation model based on the energy balance spectrum, able to accurately assess wave parameters on lakes, estuaries and coastal zones, given the bathymetry, the outline wave "clime" and wind initial conditions. The wave celerity propagation is obtained according to the linear theory ${ }^{[14]-[15]}$. The model is based on the principle that surfaces characteristics are retrievable from wave spectral variance, $E(\sigma, \theta)$, representing the wave energy distribution on angular frequencies, $\sigma$, and propagation direction, $\theta$. The model assesses the wave evolution through the action density $N(|\vec{x}|, t$; 
$\sigma, \theta)$ in space, $\vec{x}$, and time, $t$. Where the term action density, $N$, refers to the ratio between spectral variance and angular frequency, $(N=E / \sigma) . N$ temporal variation is taken into account through the first term in the left side of the balance equation (eq. 1) ${ }^{[15]-[16]}$ :

$$
\frac{\partial N}{\partial t}+\nabla_{\vec{x}} \cdot\left[\left(\vec{c}_{g}+\vec{U}\right) \cdot N\right]+\frac{\partial c_{\sigma} N}{\partial \sigma}+\frac{\partial c_{\vartheta} N}{\partial \vartheta}=\frac{S_{t o t}}{\sigma}
$$

The second term of the cinematic part of the equation (left side) accounts for the energy propagation in the surface direction, $\vec{x}$, having group celerity $\vec{c}_{g}=\partial \sigma / \partial \vec{k}$ derived by the linear dispersion equation $\sigma^{2}=g|\vec{k}| \cdot \tanh \cdot(|\vec{k}| d)$, depending on wave number vector, $\vec{k}$, and local depth, $d$. The third and fourth term represent the effect of angular frequency translation and the refraction effect, respectively, both due to depth variation and sea currents, where $c_{\sigma}$ and $c_{\theta}$ are the celerity propagation in the spectral space $(\sigma, \theta)$. The right side of the equation includes the source term, $S_{t o t}$, representing all physical processes generating, dissipating, or redistributing the wave energy.

\subsection{Maximum run-up assessment}

Once the offshore wave propagation motion has been assessed, the maximum beach run-up ${ }^{[17]}, R$, needs to be evaluated. The latter is quantified by means of an empirical relationship ${ }^{[3]}$. The relationship (2) has been set-up for sandy natural beaches having slope, $\beta_{f}$, ranging between $1.5^{\circ}$ and $10.8^{\circ}$ and average sand diameter, $d$, between 0.18 and $0.80 \mathrm{~mm}$.

$$
R=c \cdot L_{z w m}
$$

$R$ is assumed to be proportional to the vertical scale, $L_{z w m}$, of the run-up Rayleigh distribution ${ }^{[3]}$ (eq. 3 ) through a proportionality coefficient, $c$, assumed to be equal to 0.89 :

$$
L_{z w m}= \begin{cases}0.60 \cdot\left(H_{\text {orms }} \cdot L_{0}\right)^{0.5} \tan \beta_{f} & \tan \beta_{f} \geq 0.1 \\ 0.05 \cdot\left(H_{\text {orms }} \cdot L_{0}\right)^{0.5} & \tan \beta_{f}<0.1\end{cases}
$$

where:

- $H_{\text {orms }}$ is the deep water root mean square height;

- $L_{0}$ is the deep water wave length calculated using:

$$
L_{0}=g T^{2} / 2 \pi
$$

where $T$ is the average wave period.

\subsection{Tides oscillation assessment}

The sea level fluctuation due to astronomical and meteorological influences cannot be neglected. The factor of main interest is the frequent recurrence of this phenomenon with the sea storm. The increase of the sea level has a direct effect on shoreline withdrawal and an indirect effect on heights and distances of lapping waves, depending on the water depth increase.

To quantify the maximum tide level aiming to retrieve the effect of tide oscillation on the shoreline position, records of the close Porto Empedocle marigraph were used (37 $17^{\prime} 11.20^{\prime \prime} \mathrm{N}, 13^{\circ} 31^{\prime} 37.30^{\prime \prime}$ E). The station is part of the marigraph national network (Rete Mareografica Nazionale) set-up by ISPRA. The marigraph recorded homogeneous data suitable to be used within this case study during the decade ranging between the $1^{\text {st }}$ of January 1998 and the $26^{\text {th }}$ of October 2008 .

\section{STUDY AREA AND IN SITU MEASUREMENTS}

\subsection{Geological and geo-morphological characterization}

The Marsala coastal zone is a geological plane having NW-SE principal direction; its altitude is slightly decreasing from NE to SW (sea direction). The landscape is characterized by a constant and regular morphology, typical of the wide coastal planes that were modelled and smoothed by Quaternary sea action. The beach is located in the south of Marsala town and extends for approximately $3 \mathrm{~km}$ between Torre Tunna (northern headland: $37^{\circ} 45^{\prime} 32.26^{\prime \prime} \mathrm{N}, 12^{\circ} 27^{\prime} 40.00^{\prime \prime} \mathrm{E}$ ) and Torre Sibilliana (southern headland: $37^{\circ} 43^{\prime} 36.31^{\prime \prime N}, 12^{\circ} 28^{\prime} 11.23^{\prime \prime E}$ ). Geological lithology close to the ground surface, is 
made up by calcarenitic coastal sediments of Quaternary Age, which were modelled by periodic eustatic oscillation. Following a trasgressive phase during the Mean Pleistocene, a calcarenitic-sandy plate formed above the Marsala calcarenites (named Grande Terrazzo Superiore - G.T.S. after Ruggeri and Unti, $1974{ }^{[18]}$ ). Seven maritime terraces lie between the G.T.S. and a Versiliano terrace ${ }^{[19]}$ at increasing depths $(3,10,20,30,50,75$ and $100 \mathrm{~m}$ a.s.l.). Terraces were identified by alternating steps and erosion planes due to sea regression, highlighting the coastline morphology in recent geological periods. The beach is made up of monogranular thin sand $\left(10^{2}-10^{3} \mu \mathrm{m}\right)$ with sparse diagenesis in the Torre Sibilliana area ${ }^{[19]}$.

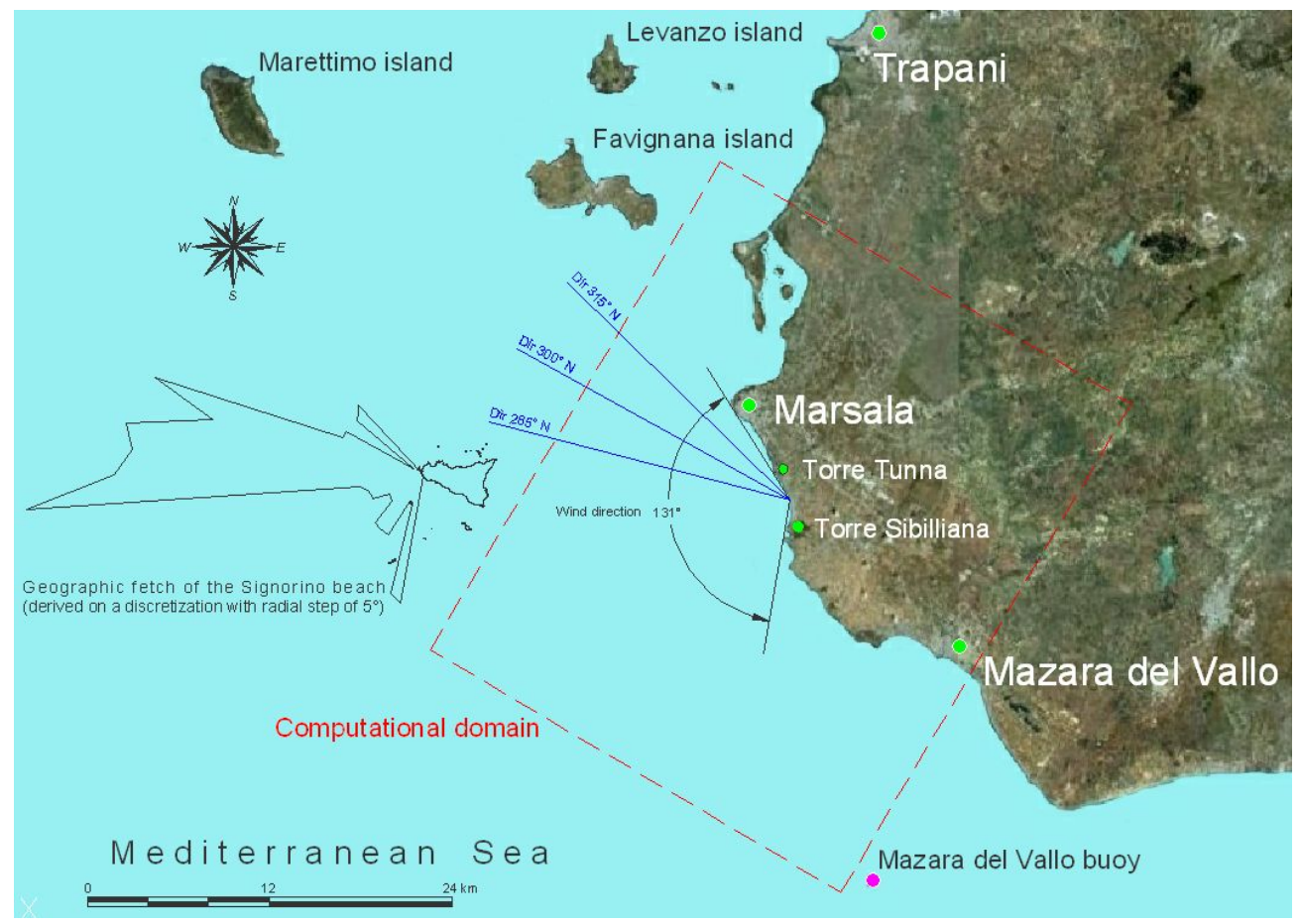

Fig. 1. Computational domain (dashed line) of the study area, with wind and critical wave directions.

\subsection{Diachronic analysis}

In order to accurately assess both linear and surface variations of Lido Signorino beach in the last 12 years, a GIS based model has been set-up. Orthophotos acquired between 1994 and 2006 built up the dataset. It includes the grey scale Volo Italia 1994 images characterized by $1 \mathrm{~m}$ nominal spatial resolution $\left(R_{S}\right)$, the color scale Volo IT $2000\left(R_{S}=1 \mathrm{~m}\right)$ and the Volo IT $2006\left(R_{S}=0.5 \mathrm{~m}\right)$. The images were georeferenced in a common projection system (UTM WGS84 33N) with an accuracy $\leq 1 \mathrm{~m}$. Surveyed beach bathymetry (May 2010) was used to represent the true bathymetry and a common reference to compare the shorelines.

Georeferenced images were mosaicked over the whole littoral zone and the shoreline was digitized for each year using a GIS platform. The shoreline accuracy was about. The comparison highlights errors due to both digitizing accuracy $(\bar{\mp} 2$ $\mathrm{m})$ as well as to the spatial resolution, georeferencing accuracy, instantaneous tide and waves.

By analysing historical displacements of the coastline, the beach ranging between Torre Tunna and Torre Sibilliana towers were sub-divided in 9 parts. Shoreline displacements were measured in transects distant $50 \mathrm{~m}$ each other.

The analysis allowed delimitating areas where the beach was diminished or risen over the study period.

\section{RESULTS}

Within this section the results of the maritime hydraulic study, the statistics of wave data, the near-shore modelling and finally the maximum run-up and tides are given. 


\subsection{Maritime hydraulic study}

By analysing the coastline morphology, the wind sector amplitude is $131^{\circ}$ and ranges between $195^{\circ}$ and $300^{\circ} \mathrm{N}$ clockwise (Fig. 1), however the close island of Favignana (the Egadi archipelago) blinds the northern part of the sector narrowing it to $105^{\circ}\left(195^{\circ} \div 300^{\circ} \mathrm{N}\right)$. The buoy records vertical oscillation within $\mp 20 \mathrm{~m}(0.01 \mathrm{~m}$ resolution and $3 \%$ accuracy) and between $0^{\circ} \div 360^{\circ}\left(1.5^{\circ}\right.$ resolution and $0.5^{\circ} \div 2^{\circ}$ accuracy). The buoy is the only one available close to the chosen littoral zone and is managed by the Superior Institute for Environmental Protection and Research (ISPRA Istituto Superiore per la Protezione e la Ricerca Ambientale) delivering the data. Wave heights, $H_{s}[\mathrm{~m}]$, maximum and mean wave periods, $T_{p}$ and $T_{m}$ [s] and wave direction, $D_{m}\left[{ }^{\circ} \mathrm{N}\right]$, between the $1^{\text {st }}$ of July 1989 and $4^{4 \mathrm{th}}$ of April 2008 were acquired and processed applying a geographic transposition, to take into account the differences in wind exposition between the beach and the boundary of the calculation domain. A wave propagation analysis from off to near -shore allows the retrieval of the beach run-up.

\subsection{Statistical analysis of wave data}

The ordinary value has been assumed as the minimum of the peak values for each sea-storm, since it is reached at least once a year during the observational period. The shoreline analysis has been carried out on the $285^{\circ} \mathrm{N}$ direction, characterized by the more frequent sea-storms and higher peaks. Between the latter, the minimum value was reached in $2001(H=2.18 \mathrm{~m})$ with a period $T=5.51 \mathrm{~s}$ (Tab. 1$)$.

Tab. 1. Sea-storm peak, Hs [m], and minimum value, for each year of records and for given propagation direction.

\begin{tabular}{|c|c|c|c|c|c|}
\hline Direction & $\mathbf{1 9 5}^{\circ} \mathbf{N}$ & $\mathbf{2 2 5}^{\circ} \mathbf{N}$ & $\mathbf{2 5 5}^{\circ} \mathbf{N}$ & $\mathbf{2 8 5}^{\circ} \mathbf{N}$ & $\mathbf{3 1 5}^{\circ} \mathbf{~}$ \\
\hline $\mathbf{1 9 8 9}$ & - & - & - & 3.49 & - \\
\hline $\mathbf{1 9 9 0}$ & 2.00 & 3.09 & - & 5.89 & 3.62 \\
\hline $\mathbf{1 9 9 1}$ & - & - & 2.31 & 6.26 & 2.36 \\
\hline $\mathbf{1 9 9 2}$ & - & 4.30 & 3.27 & 4.25 & 3.99 \\
\hline $\mathbf{1 9 9 3}$ & - & 5.15 & 3.27 & 6.87 & 4.01 \\
\hline $\mathbf{1 9 9 4}$ & 1.88 & - & 2.09 & 4.97 & 4.18 \\
\hline $\mathbf{1 9 9 5}$ & - & - & - & 6.10 & 3.73 \\
\hline $\mathbf{1 9 9 6}$ & 2.30 & - & - & 6.00 & - \\
\hline $\mathbf{1 9 9 7}$ & - & - & - & 4.43 & 3.66 \\
\hline $\mathbf{1 9 9 8}$ & 2.50 & 1.85 & 2.53 & 7.19 & 3.90 \\
\hline $\mathbf{1 9 9 9}$ & - & 2.45 & - & 2.67 & 6.27 \\
\hline $\mathbf{2 0 0 0}$ & - & 2.33 & 2.49 & 2.55 & 4.44 \\
\hline $\mathbf{2 0 0 1}$ & - & 2.26 & 2.88 & 2.18 & 5.15 \\
\hline $\mathbf{2 0 0 2}$ & - & - & - & 4.64 & - \\
\hline $\mathbf{2 0 0 3}$ & - & - & - & - & - \\
\hline $\mathbf{2 0 0 4}$ & - & 5.43 & - & 5.54 & 2.92 \\
\hline $\mathbf{2 0 0 5}$ & 3.72 & 5.64 & 2.52 & 6.16 & - \\
\hline $\mathbf{2 0 0 6}$ & 1.91 & 1.84 & - & 6.34 & 4.04 \\
\hline $\mathbf{2 0 0 7}$ & - & - & 3.80 & 5.14 & - \\
\hline $\mathbf{2 0 0 8}$ & - & 2.25 & 3.55 & 3.92 & - \\
\hline $\mathbf{M i n}$ & 1.88 & 1.85 & 2.09 & 2.18 & 2.36 \\
\hline & & & & & \\
\hline
\end{tabular}

\subsection{The SWAN model}

A grid having a spatial resolution of $100 \mathrm{~m}$ has been used to simulate near-shore waves ${ }^{[20]}$. The wind effect wasn't taken into account; on the contrary the dissipative term produced by breaking was included within the source terms. The significant height, period and propagation direction of the input waves were respectively assumed equal to: $2.18 \mathrm{~m}, 5.51$ $\mathrm{s}$ and $285^{\circ} \mathrm{N}$. The graphical output of a generic simulation is reported in Figure 2. By analysing those data, the significance height $H_{s}=1.80 \mathrm{~m}$ and period $T=4.43 \mathrm{~s}$ for given bathymetry $(-60 \mathrm{~m})$ have been retrieved, that were successively used for the run-up assessment. 


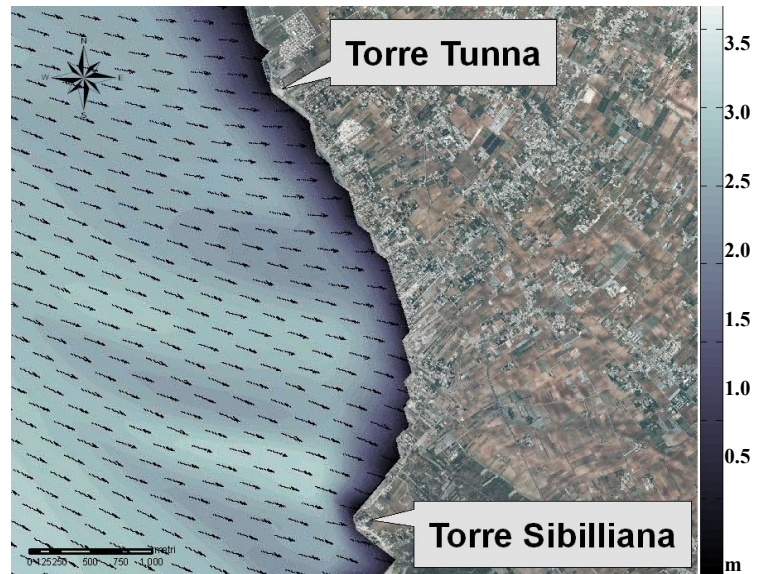

Fig. 2. SWAN outputs: arrows indicating the waves propagation direction over imposed to the significance waves height [m] shown by a colour scale.

\subsection{Maximum run-up and tide effects assessment}

The average slope of the foreshore beach is $\tan \beta_{f}=0.0359$ (Figure 3), and assuming $H_{\text {orms }}=1.27 \mathrm{~m}\left(\equiv 0.706 H_{s}\right)$, maximum wave run-up is estimated to be about $7.73 \mathrm{~m}$. As reported in the literature, the used equation gives a run-up greater than the actual value; therefore the authors are currently implementing a more complex model to estimate the run-up more accurately.

\section{Beach profile}

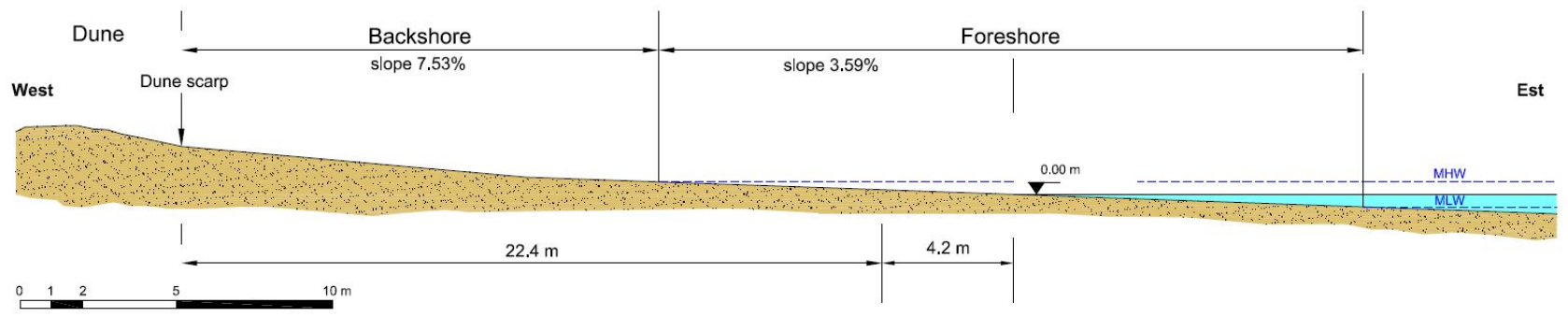

Fig. 3. Vertical profile, orthogonal to the shoreline, of Lido Signorino beach (Marsala).
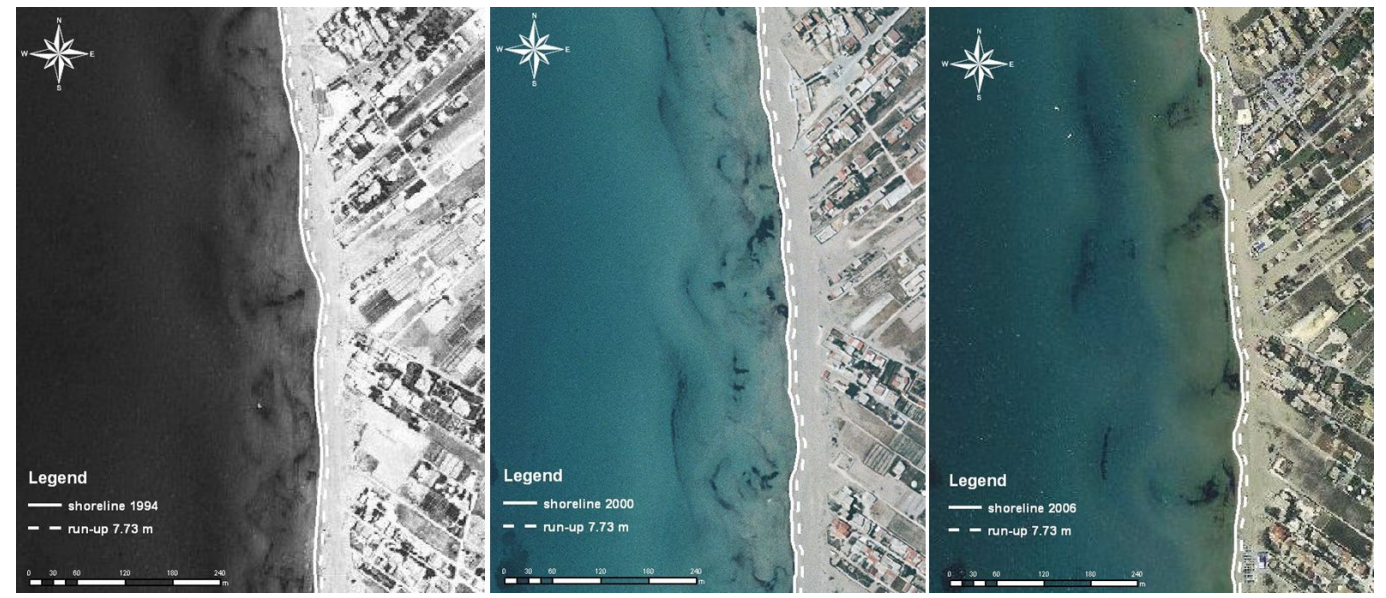

Fig. 4. Shoreline position and maximum run-up during the 1994 (left panel), 13/05/1999 (central panel) and 27/08/2005 (right panel) acquisitions. 
Since maxima fluctuations within the study period resulted in about $\mp 0.4 \mathrm{~m}$ and the average beach slope is $3.59 \%$ (Figure 3) the shoreline positioning uncertainty due to tide variation is $\sim \mp 10 \mathrm{~m}$.

\section{DISCUSSION AND CONCLUSIONS}

The proposed methodology, even if in a preliminary phase, allows evaluating tides and waves influence in positioning the shoreline through remotely sensed images. These are often the only tools available to build-up the morphological evolution of a beach in the last decades with sufficient accuracy. Shoreline positioning through airborne images are often affected by uncertainty in the user visual interpretation of the wet/dry boundary of a beach, due to both waves and images characteristics at the acquisition time. The study case shows that wave motion, together with local sea characteristics, produces a positioning error of about 15 meters. Shoreline and run-up delimit a zone strictly dependent on ordinary sea storm, during which they are both submerged and that therefore should be assumed as respect zone and should undergoes the rules of the maritime State property. Uncertainties due to sea level fluctuation, causing an error of $\approx 10 \mathrm{~m}$, must be superimposed to those caused by the run-up $(\approx 7.7 \mathrm{~m})$. Methodology limits are strictly related to offshore buoy data quality and availability. Run-up has been estimated using an empirical relationship retrieving an accurate value, even if the implementing of a hydraulic model to verify shoreline position is actually in progress. However the knowledge of maritime conditions during the remote sensing overpass is fundamental to rigorously verify the positioning.

\section{REFERENCES}

[1] Martin, B., Jack Davis, J., Kress, R., Ebersole B., and Curtis W.R., [Coastal Engineering Manual], CEM, Washington, (2002).

[2] Boak, E.H. and Turner, I.L., "Shoreline definition and detection: a review", Journal of Coastal Research, 18, 1-13, (2005).

[3] Neilsen, P., and Hanslow, D. J., "Wave run-up distributions on natural beaches", J. Coastal Res., Papers 7, 11391152, (1991).

[4] Baldock, T.E., Weir, F., and Hughes, M.G., "Morphodynamic evolution of a coastal lagoon entrance during swash overwash", Geomorphology 95, Issues 3-4, 15, 398-411, (2008).

[5] Andrèfouët, S., Robinson, J.A., Hu, C.M., Feldman, G.C., Salvat, B., Payri, C. And Muller-Karger, F.E., "Influence of the spatial resolution of SeaWiFS, Landsat-7, SPOT, and International Space Station data on estimate of landscapes parameters of Pacific Oceans atolls". Canadian Journal of Remote Sensing, 29, 210-218, (2003).

[6] Lee, J.S., and Jurkevich, I., "Coastline detection and tracing in SAR images", IEEE Transaction on Geoscience and Remote Sensing, 28, 662-668, (1990).

[7] Baghdadi, N., Gratiot, N., Lefebvre, J.P., Oliveros, C. and Bourguignon, A., "Coastline and mudbank monitoring in French Guaiana: contribution of radar and optical satellite imagery" Canadian Journal of Remote Sensing, 30, 109122, (2004).

[8] Kim, D.J., Moon, W.M., Park, S.E., Kim, J.E. and Lee, H.S., "Dependence of waterline mapping on radar frequency used for SAR images in intertidal areas ", IEEE Geoscience and Remote Sensing Letters, 4, 269-273, (2007).

[9] Liu, H., Sherman, D. and Gu, S., "Automated extraction of shoreline from airborne light detection and ranging data and accuracy assessment based on Monte Carlo simulation" Journal of Coastal Research, 23, 1359-1369, (2007).

[10] Lee, D.S. and Shan, J.,"Combining Lidar Elevation Data and IKONOS multispectral imagery for coastal classification mapping", Marine Geodesy, 26,105-115, (2003).

[11] Deronde, B., Houthuys, R., Debruyn, W., Fransaer, D., Van Lancker, V. and Henriet, J.P., "Use of airborne hyperspectral data and laserscan data to study beach morphodynamics along the Belgian coast", Journal of Coastal Research, 22, 1108-1117, (2006).

[12] Corsini, S. and Inghilesi, R., [Atlante delle onde nei mari italiani], APAT, Roma, 5, (2006).

[13] Boccotti, P., [Idraulica Marittima], UTET, Torino, (2008).

[14] Whitham, G.B., [Linear and Nonlinear Waves], John Wiley and Sons Inc., New York, (1974).

[15] Mei, C.C., [The applied dynamics of ocean surface waves], John Wiley, New York, (1983).

[16] Komen, G.J., [Dynamics and Modelling of Ocean waves], Cambridge University Press, 532, (1994).

[17] Stockdon, H.F., Holman, R.A., Howd, P.A., Sallenger Jr, A.H., "Empirical parameterization of setup, swash and runup", Coastal Engineering, Papers 53 (7), 573-588, (2006).

[18] Ruggieri, G., and Unti, M., "Pliocene e Pleistocene nell'entroterra di Marsala". Bollettino Società Geologica Italiana 93, 723-733, (1974). 
[19] D'Angelo, U., and Vernuccio, S., "I terrazzi marini quaternari dell'estremità occidentale della Sicilia", Mem. Soc. Geol. It., 585-594, (1996).

[20] Zijlema, M., "Computation of wind-wave spectra in coastal waters with SWAN on unstructured grids", Coastal Engineering, 57, 267-277. (2010). 